\title{
IS ALLERGIC RHINITIS A FACTOR THAT AFFECTS SUCCESS OF TYMPANOPLASTY?
}

\author{
Elif Ersoy Callioglu', A. Sami Bercin', Hayati Kale ${ }^{2}$, Togay Muderris ${ }^{1}$, \\ Sule Demirci', Arzu Tuzuner', M. Hakan Korkmaz ${ }^{2}$
}

Department of Otolaryngology, Ministry of Health Ataturk Training and Research Hospital, Ankara,Turkey ${ }^{1}$; Department of Otolaryngology, Yildirim Beyazit University Faculty of Medicine, Ankara, Turkey²; Department of Otolaryngology, Ministry of Health Ankara Training and Research Hospital Ankara, Turkey ${ }^{3}$

Summary: Objective: The aim of the present study was to investigate the effect of allergic rhinitis on the success of the operation in chronic otitis surgery by using score for allergic rhinitis (SFAR). Materials and Methods: In the present study; 121 patients, who underwent type 1 tympanoplasty were examined retrospectively. SFAR of all patients were recorded. The graft success rates of 26 patients with allergic rhinitis (AR) and 95 patients with no allergic rhinitis group (NAR) were compared. Results: While the graft success rate in NAR group was $89.5 \%$, this rate was $80.8 \%$ in the AR group. However, the difference between groups was not statistically significant $(p=0.311)$. Conclusion: These findings suggest that allergic rhinitis decreases the graft success rate of the pathologies occurring in eustachian tube, middle ear and mastoid although statistically significant difference wasn't found. Prospective studies with larger patient groups are required in order to evaluate this pathology.

Keywords: Allergic rhinitis; Tympanoplasty; Graft success rate; Chronic otitis surgery; Middle ear pathology

\section{Introduction}

Since the first application of tympanoplasty in chronic otitis surgery by Zöllner (1) and Wullstein (2) in 1952, various graft materials and techniques have been used. Today, despite different operation techniques and grafts, success rates still vary widely $(3-5)$. Graft success rates are affected by various factors such as perforation size and the type of middle ear pathology (chronic tubal dysfunction, pathological middle ear mucosa).

Negative effects of nasal mucosa pathologies and eustachian tube dysfunction on middle ear and mastoid are known (6-10). It has been shown in various studies that allergic rhinitis affects nasal mucosa and eustachian tube functions (6-10). Just as allergic reaction affects the nasal mucosa and nasopharyngeal mucosa, it can also affect the middle ear and eustachian tube mucosa (8-11). In numerous studies, it was shown that there is an increase in allergic rhinitis prevalence in the patients with chronic otitis media with effusion $(11,12)$. Allergic rhinitis has a high prevalence $(10 \%$ and $54 \%)$ and its effects on middle ear and eustachian functions are well recognized. However its effect on the operation success in chronic otitis surgery has not been investigated (13-15). Allergic symptom history, in vivo and in vitro tests are used in the diagnosis of allergic rhinitis (16). However in the studies performed, it has been shown that $\operatorname{SFAR}(17,18)$ correlates with standard diagnostic tests and it can also be used in the diagnosis and treatment of allergic rhinitis.

In patients undergoing tympanoplasty operation, demographical characteristics and middle ear pathologies were similar. Graft success rates were compared in the patients with and without allergic rhinitis by using the SFAR score.

\section{Materials and Methods}

In the present study, 121 patients with type 1 tympanoplasty were retrospectively examined between 2008 and 2013. Detailed history was taken from the patients and micro otoscopic physical examinations and laboratory tests were carried out. After the evaluations of all patients were completed, SFAR was recorded. Allergic rhinitis patient group consists of the patients with the score of 7 or more, as defined (Table 1). The patients, who did not have medical treatment of allergic rhinitis before operation, were included in the study. Treatment of allergic rhinitis was not given in postoperative early period.

There were 26 patients in the allergic rhinitis group (AR) and 95 patients in no allergic rhinitis group (NAR). Perforations in these patients consist of subtotal perforations with over $75 \%$ of the tympanum membrane surface area. The patients with ossicular chain defect, pathological middle ear mucosa, cholesteatoma, tympanosclerosis and otorrhea are excluded from the study. All of the patients had preoperative 
Tab. 1: SFAR (Score For Allergic Rhinitis) (17).

\begin{tabular}{|l|c|c|}
\hline Items/discriminators & Score & Cumulative score \\
\hline Blocked nose, runny nose, sneezing in past year (nasal symptoms) & 1 for each symptom & 3 \\
\hline Months of the year & $\begin{array}{c}1 \text { for perennial } \\
1 \text { for pollen season }\end{array}$ & 5 \\
\hline Nasal symptoms plus itchy eyes (rhinoconjunctivitis) & 2 & 7 \\
\hline $\begin{array}{l}\text { Triggers: Pollens, house dust mites, dust } \\
\text { Epithelia (cat, dog) }\end{array}$ & 2 & 9 \\
\hline Perceived allergic status & 1 & 11 \\
\hline Previous positive allergic tests & 2 & 13 \\
\hline Previous medical diagnosis of allergy & 2 & 14 \\
\hline Familial history of allergy & 1 & 16 \\
\hline Total points & 2 & 16 \\
\hline
\end{tabular}

temporal CT examinations and those with mastoid pathology were excluded from the study.

When all the patients were evaluated, follow-up period was determined to vary between 1 and 4 years. Average follow-up period of the patients in AR group was 2.5 (1-4) years and average follow-up period of the patients in NAR group 3 (1-4) years. The graft success rates of type 1 tympanoplasy in 26 patients with allergic rhinitis (AR) (14 F, $12 \mathrm{M}$ average $36.9 \pm 14.7)$ and 95 patients with no allergic rhinitis group (NAR) (51 F, $44 \mathrm{M}$, average $31.6 \pm 13.3)$ were compared.

Type 1 tympanoplasty operation was performed on 27 patients by using chondroperichondrial island graft and on 94 patients by using temporal muscle fascia. Operation procedure was standardized for both groups. Under general anesthesia, over-underlay technique was used by a postauricular approach. We used classical "over underlay" technique with cartilage and fascia. The graft was placed over malleus and under the annulus.

The patients were called for the controls in the postoperative first, second weeks and in the first month. In postoperative second week, spongostane and pomades with antibiotics in the external ear way of the patients were aspirated. No antibiotics were given preoperatively to the patients in neither of the groups. But oral penicillin was given to all patients postoperatively for 7 days in both groups. Then patients were followed with monthly follow-up.

The repair of tympanic membrane perforation was considered as success criterion of the operation. Reperforation was observed in 5 patients in AR group and in 10 patients in NAR group.

\section{Statistical analysis}

Data analysis was performed by using SPSS for Windows, version 11.5 (SPSS Inc., Chicago, IL, United States). Whether the distributions of metric discrete variables was normal or not was determined by Kolmogorov Smirnov test.
Data were expressed as mean $\pm \mathrm{SD}$ or median (min-max), where applicable. While the mean differences between groups were compared by Student's t test, otherwise, Mann Whitney U test was used for comparisons of the median values. Categorical data were analyzed by Pearson's Chi-square or Fisher's exact test, where appropriate. A p value less than 0.05 was considered statistically significant.

\section{Results}

Graft success rates of 26 patients in AR group who underwent type 1 tympanoplasty and 95 patients in NAR group were compared. When the groups were examined in terms of demographical properties; no statistically significant difference was observed $(p>0.05)$ (Table 2$)$. No statistically significant difference was found between the groups in terms of gender, age, control period etc.

Tab. 2: Demographical characteristics.

\begin{tabular}{|l|c|c|c|}
\hline Variables & $\begin{array}{c}\text { NAR } \\
(\mathbf{n = 9 5})\end{array}$ & $\begin{array}{c}\text { AR } \\
(\mathbf{n}=\mathbf{2 6})\end{array}$ & p-value \\
\hline Age (years) & $31.6 \pm 13.3$ & $36.9 \pm 14.7$ & $0.079 \dagger$ \\
\hline Gender & & & $0.988 \dagger$ \\
\hline Male & $44(46.3 \%)$ & $12(46.2 \%)$ & \\
\hline Female & $51(53.7 \%)$ & $14(53.8 \%)$ & \\
\hline $\begin{array}{l}\text { Follow-up times } \\
\text { (years) }\end{array}$ & $3(1-4)$ & $2.5(1-4)$ & 0.406 \\
\hline
\end{tabular}

$\dagger$ Student’s t test, $\$$ Pearson's chi-square test, $₫$ Mann Whitney U test.

Average allergic rhinitis symptom score of 26 patients with allergic rhinitis was calculated as $10(7-15)$ while that of 95 patients with no allergic rhinitis was 4 (1-6) (Table 3).

When the fascia and cartilage graft usage rates were compared in both groups, no statistically significant difference was found $(\mathrm{p}=0.151)$ (Table 4). 
Tab. 3: Descriptive statistics for SFAR scores.

\begin{tabular}{|l|c|c|}
\hline SFAR score & NAR & AR \\
\hline Number of cases & 95 & 26 \\
\hline Mean & 3.6 & 10.5 \\
\hline SD & 1.34 & 2.32 \\
\hline Median & 4 & 10 \\
\hline Minimum & 1 & 7 \\
\hline Maximum & 6 & 15 \\
\hline
\end{tabular}

Tab. 4: The types of tympanoplasty in groups.

\begin{tabular}{|l|c|c|c|}
\hline & $\begin{array}{c}\text { NAR } \\
(\mathbf{n = 9 5})\end{array}$ & $\begin{array}{c}\text { AR } \\
(\mathbf{n = 2 6 )}\end{array}$ & p-value \\
\hline Tympanoplasty & & & $0.151 \dagger$ \\
\hline Fascia & $75(78.9 \%)$ & $17(65.4 \%)$ & \\
\hline Cartilage & $20(21.1 \%)$ & $9(34.6 \%)$ & \\
\hline
\end{tabular}

$\uparrow$ Pearson's chi-square test.

When the graft success rates were evaluated, while perforation ratio in the patients with allergic rhinitis $( \pm)$ was $19.2 \%$, it decreased to $10.5 \%$ in the patients with no allergic rhinitis. However, there was no statistically significant difference between groups $(\mathrm{p}=0.311)$ (Figure 1).

No statistically significant difference was found between AR and NAR groups in terms of average age in patients with successful grafts $(p=0.146)$. No statistically significant difference was found between AR and NAR groups in terms of average age in patients with perforated grafts $(\mathrm{p}=0.251)$.

Average age of patients with perforated grafts was statistically significant lower than patients with successful grafts in NAR group $(p=0.007)$. No statistically significant difference was found between patients with perforated grafts and patients with successful grafts in terms of average age in AR group ( $p=0.727)$ (Table 5).

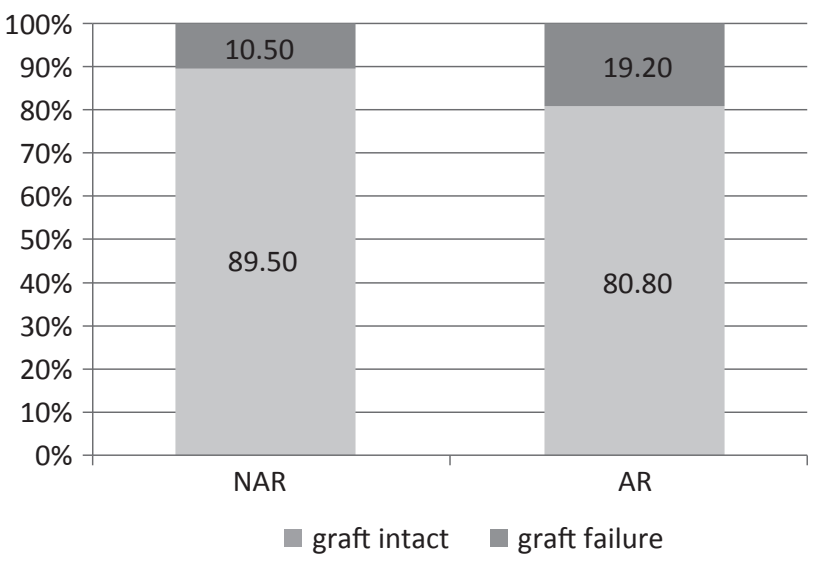

Fig. 1: Comparison of the graft success rate between the AR and NAR groups.
Tab. 5: Mean ages regarding for both allergic rhinitis and graft success.

\begin{tabular}{|c|c|c|c|}
\hline & NAR & AR & $p$-value $+q$ \\
\hline Intact & $32.6 \pm 13.5$ & $37.4 \pm 14.0$ & 0.146 \\
\hline Perforated & $23.2 \pm 8.3$ & $34.8 \pm 19.0$ & 0.251 \\
\hline p-value $\$ \mathbb{1}$ & 0.007 & 0.727 & \\
\hline
\end{tabular}

$\dagger$ The comparisons between NAR and AR groups, according to the Bonferroni Correction $p<0.025$ was considered as statistically significant, $\$$ The comparisons between Intact and Perforated groups, according to the Bonferroni Correction $\mathrm{p}<0.025$ was considered as statistically significant, $\uparrow$ Student's t test.

\section{Discussion}

Prevalence of allergic rhinitis in the population varies between $10 \%$ and 54\% (13-15). Despite its high prevalence and its negative effects on the middle ear and mastoid, its effect in chronic otitis surgery has not been investigated. It is not considered in surgery planning and evaluation of success criteria. To our knowledge, the present study is the first one in the literature investigating the effect of allergic rhinitis on tympanoplasty operation success.

Success rates in tympanoplasty still show variance despite various operation techniques and different grafts $(4,5$, 19). Success rates in the literature vary depending on various factors such as the perforation size, weight of the middle ear pathology (chronic tubal dysfunction, pathological middle ear mucosa), technique applied, monitorization period, change in the number of cases etc.

Chronic tubal dysfunction has an important role between such factors. Effect of allergic rhinitis on nasal mucosa and eustachian tube functions is shown in various studies (6-10). Mediators and cytokines released during allergic reaction cause nasal and nasopharyngeal edema and hyper secretion, leading to eustachian dysfunction (8-11). In the studies performed so far; it has been shown that there is an increase in allergic rhinitis prevalence in the patients with chronic otitis media with effusion $(11,12,20)$. In the study of Pelikan et al. (11), it was shown in 87 patients with chronic secretory otitis media that nasal allergy affects eustachian tube functions and middle ear pressure changes, causing deterioration of hearing functions. In the study of Alles et al. (12) performed in 209 children with chronic otitis media with effusion; prevalence of allergic rhinitis was found to be $89 \%$. The role of allergy in otitis media with effusion can be correlated to various mechanisms. Exposure of middle ear mucosa to allergic reaction, nasal and nasopharyngeal inflammation and obstruction of the edema occurring in the eustachian tube and transmission of the bacteria from nasopharynx to the middle ear via hyper secretion due to allergic reaction are the essential factors.

In the diagnosis of allergic rhinitis; typical allergic symptom history and diagnostic tests are used (16). Diagnostic laboratory tests are in vivo (specific IgE etc.) and in vitro (skin tests) tests (16). SFAR (17) is an efficient test in the 
determination of allergic rhinitis prevalence defined in 2002. In the studies performed; it was shown that SFAR correlates with standard diagnostic tests and that it can be used in the diagnosis and treatment of allergic rhinitis $(17,18)$. Ologe et al. (18) has stated that $94.8 \%$ sensitivity and $95.1 \%$ specificity can be obtained in allergic rhinitis diagnosis by using SFAR. In the present study; average allergic rhinitis symptom score of 26 cases with allergic rhinitis was $10.46 \pm 2.32$.

Graft success rates in the literature show variability (4, 19, 21). After 24-months of follow-up; Cabra et al. (4) found a success rate of $82 \%$ in the patients subjected to palisade cartilage tympanoplasty and $64 \%$ in the patients subjected to fascia tympanoplasty. Locovou et al. (19) have reported a success rate of $97.2 \%$ in their study in 2014 performed by using cartilage graft. Cavaliere et al. (5) have reported 100\% success ratio in tympanoplasty performed by using cartilage shield graft in the study consisting of 236 patients. Such variation in success rates can be due to the technique applied, follow-up period and the variability in the number of cases. In the present study; while the graft success rate was $89.5 \%$ in the NAR group, it was found to be $80.8 \%$ in the AR group $(p=0.311)$. These findings suggest that allergic rhinitis decreases the graft success rate of the pathologies occurring in the nasal mucosa, eustachian tube, middle ear and mastoid, although statistically significant difference wasn't found. Studies with higher number of patients can show statistically significant difference. This pathology should be investigated in chronic otitis media surgery because of its active role in pathogenesis of secretory otitis media which has high prevalence (11-13). Studies with larger number of cases are required in order to evaluate this issue more thoroughly.

\section{Conclusion}

These findings suggest that allergic rhinitis decreases the graft success rate of the pathologies occurring in nasal mucosa, eustachian tube, middle ear and mastoid although statistically significant difference wasn't found. Prospective studies with larger patient groups are required in order to evaluate this pathology that influences middle ear and mastoid bone considerably.

\section{References}

1. Zöllner F. The principles of plastic surgery of the sound-conducting apparatus. J Laryngol Otol 1955; 69: 657-9.

2. Wullstein HL. Funktionelle operation in mittelohr mit hilfe des frejen spaltlappentranplantetes. Arc Ohren Nasen Kehlkopfheilkd 1952; 161: 22-35.

3. Dornhoffer JL. Hearing result with cartilage tympanoplasty. Laryngoscope 1997; 107: 1094-9.

4. Cabra J, Monux A. Efficacy of cartilage palisade tympanoplasty: randomized controlled trial. Oto Neutorol 2010 Jun; 31(4): 589-95.

5. Cavaliere M, Mottola G, Rondinelli M, Iemma M. Tragal cartilage tymoanoplasty: anatomic and fuctional result in 306 cases. Acta Otolaryngol Ital 2009; 29 : $27-32$.

6. Skoner DP, Casselbrant ML. Otitis media. In: Middleton E Jr, Reed ChE, Ellis EF, et al, eds. Allergy, Principles \& Practice. 5th ed. St. Louis, MO: Mosby Year Book Inc, 1998: 1036Y49.

7. Fireman P. Otitis media. In: Kay AB, ed. Allergy and Allergic Diseases. 1st ed. Oxford: Blackwell Sci Publ, 1997: 1632Y44.

8. Fireman P. Otitis media and eustachian tube dysfunction: Connection to allergic rhinitis. J Allergy Clin Immunol. 1997 Feb; 99(2): S787-97.

9. Stuar M. Late phase allergy and eustachian tube dysfunction. Otolaryngol Head Neck Surg. 2001 Oct; 125 (4): 339-45.

10. Doyle WJ. The link between allergic rhinitis and otitis media. Curr Opin Allergy Clin Immunol 2002 Feb; 2(1): 21-5.

11. Pelikan Z. Audiometric Changes in Chronic Secretory Otitis Media Due to Nasal Allergy. Otology \& Neurotology 2009 Oct; 30(7): 868-75.

12. Alles R, Parikh A, Hawk L, Darby Y, Romero JN, Scadding G. The prevalence of atopic disorders in children with chronic otitis media with effusion. Pediatr Allergy Immunol 2001: 12: 102-106.

13. Bousquet J, van Cauwenberge P, Khaltaev N. ARIA Workshop Group; World Health Organization. Allergic rhinitis and its impact on asthma. J Allergy Clin Immunol 2001; 108(5) (suppl): S147-S334

14. Asher M, Montefort S, Bjorksten B, et al. Worldwide time-trends in the prevalence of symptoms of asthma, allergic rhinoconjuctivitis, and eczema in childhood: ISAAC phases one and three repeat multicountry cross sectional surveys. Lancet 2006; 26: 733-743.

15. Katelaris $\mathrm{CH}$, Lee BW, Potter PC, et al. Prevalence and diversity of allergic rhinitis in regions of the world beyond Europe and North America. Clin Exp Allergy 2012 Feb; 42(2): 186-207.

16. Bousquet J, Khaltaev N, Cruz AA, et al. Allergic Rhinitis and its Impact on Asthma (ARIA) 2008 update (in collaboration with the World Health Organization, GA 2 LEN). Allergy 2008; 63(suppl 86): 8-160.

17. Annesi-Maesano I, Didier A, Klossek M, Chanal I, Moreau D, Bousquet J. The score for allergic rhinitis (SFAR): a simple and valid assessment method in population studies. Allergy 2002 Feb; 57(2): 107-14.

18. Ologe FE, Adebola SO, Dunmade AD, Adeniji KA, Oyejola BA. Symptom score for allergic rhinitis. Otolaryngology - Head and neck surgery 2013 Apr; 148(4): $557-63$.

19. Lacovou E, Kyrodimos E, Sismanis A Cartilage "shield" tympanoplasty: an effective and practical technique. Eur Arch Otorhinolaryngol 2014 Jul; 271(7): 1903-8.

20. Damm M, Jayme KP, Klimek L. Recurrent otitis media with effusion in childhood: when should an otolaryngologist consider an allergic etiology? HNO 2013 Oct; 61(10): 843-8.

21. Khan MM, Parab SRJ. Comparative study of sliced tragal cartilage and temporalis fascia in type I tympanoplasty. Laryngol Otol 2015 Jan; 129(1): 16-22.

Received: 05/10/2015

Accepted in revised form: 30/01/2016

\section{Corresponding author:}

Elif Ersoy Callioglu, Ministry of health Ataturk Training and Research Hospital, Bilkent Ankara, Turkey; e-mail: elifersoy78@hotmail.com 